\title{
Reasonable Organization and Optimized Design of Production Logistics in Industrial Manufacturing Enterprises
}

\author{
Yuanqing $\mathrm{Hu}$ \\ Hunan Modern Logistics College \\ Changsha, China 410131
}

\begin{abstract}
There are a large number of optimized decisions of production logistics in the production and management of manufacturing enterprises. Scientific organization, optimized production logistics process, flexible manufacturing, reduced cost and increased efficiency is the important path to realize enterprise's sustainable development under low-carbon economic environment. The organization and optimization of production logistics is analyzed in this paper from three aspects of space, time and personnel, so as to provide reference for the production operation and logistics management of manufacturing enterprises.
\end{abstract}

Keywords—production logistics; space organization; time organization

\section{INTRODUCTION}

In the supply chain with manufacturing enterprises as the core, there is a great quantity of optimized decision issues about production logistics. Production logistics is unique in manufacturing enterprises and is synchronize with production flow. Production is closely related to logistics, which is a belt connecting various links of production and manufacturing and also an important link for reducing cost and increasing efficiency in the production process. More and more enterprises have realized that the optimization of production logistics management is conductive to cost reduction and new profit growth point expansion.

\section{RELATION BETWEEN PRODUCTION OPERATION AND PRODUCTION LOGISTICS ORGANIZATION}

Factors influencing production logistics mainly include:

- $\quad$ production process and production type

Different production process and production type have different production structure, complexity, precision grade, process requirement, raw materials procurement and the material transfer type. All of these characteristics have an effect on the organization and scheduling of production and logistics.

- $\quad$ production scale and production mode

Production scale refers to the total product quantity within the unit time; the larger the production scale, the more complete the production structure, and the larger the logistics quantity, the more prominent the effective coordination of production and logistics. The production mode can be divided into single-piece and small-batch production, multi-varieties and small-batch production, and mass production. Production scale and production mode play a crucial role in optimizing the structure of production logistics.

- $\quad$ production specialization and coordination level

The enterprise products have a high level of specialization and the logistics process also has high repeatability and stability under the mass production condition. There is an internal relation between production logistics and the level of enterprise specialization.

The traditional production process management mainly focuses on the manufacturing process, neglecting the logistics activities linking various production technologies. In fact, logistics costs more time than that of the actual processing in the production cycle. As a result, there is a great potential in reducing cost and increasing efficiency for production logistics The smooth circulation of in-process products and production cycle shortening may be realized with balanced and stable production logistics. The optimization of in-process products inventory and balanced equipment load also relate to the management and controlling of production logistics.

The production logistics organization of process manufacturing and discrete manufacturing is analyzed in this paper to provide reference to the production operation and logistics management of manufacturing enterprises.

The production logistics process, from material input to finished products output, generally includes technological process, inspection process, transport process, waitingstopping process and other natural processes. In order to improve production efficiency, the production logistics is generally organized from the perspectives of space, time and personnel.

\section{Space Organization of Production Logistics}

The space organization of production logistics is performed in the light of the enterprise production space, and its goals mainly include effective utilization of space, shortest displacement distance of operation, and convenient and safe 
operation environment. There are three typical specialized production and organization forms, namely technology specialization, object specialization and group technology.

\section{A. Organizing the Production Logistics by Technology Specialization Form}

Technology specialization form is also referred to as technology principle. It is characterized by gathering together the production equipment with same functions to perform same technological treatment of various products to be processed. In other words, the processing targets are diversified, but the processing technology and method remains the same.

The advantages of it are strong adaptive ability to the changes of product varieties and the changes of processing order, high reliability of production system, and convenient management of technology and equipment. Disadvantages include complex material flow and route in the processing process, which is hard to coordinate. It is suitable to organize production logistics according to technology specialization under the condition of small production scale, single-piece production with low production specialization.

\section{B. Organizing Production Logistics by Object Specialization Form}

The object specialization form is also referred to as product specialization or flow line. It is characterized by organizing the production equipment and auxiliary equipment as per the processing route of the production object. In other words, the processing object is simple, but processing technologies and methods are diversified. The virtues include reduced transport times, shortened handling route, simple coordination relation and simplified production management. Defects include poor adaptability to the change of varieties, complex management of technology and equipment. Organizing production logistics according to product specialization is appropriate under the conditions of stable product varieties, mass production and complete equipment with adequate load.

\section{Organizing Production Logistics by Group Technology Forms}

Group technology form integrates the features of the above two forms, divides the parts with similarities into a group production unit, and organizes equipment according to the processing technological route. The main advantages of it lie in highly simplified processing flow of the parts, reduced roundabout route, and certain batch production on the basis satisfying variety changes, excellent production flexibility and adaptability.

The above three forms of production logistics organization have their own characteristics, yet the selection of them mainly depends on the relation between product and quantity in production system.

\section{TIME ORGANIZATION OF ProdUCtion Logistics}

Time organization of production logistics refers to the connection and integration type of various production units and procedures in terms of time in the production process of a batch of materials. To have a reasonable production logistics organization, we should not only shorten the material flow distance, but also accelerate the material flow speed and reduce the waiting time of materials, so that the materials may flow in a rhythmic and continuous way.

There are three typical forms of movement organization for the materials on manufacturing enterprise's production line, namely, sequential movement, parallel movement, parallel and sequential movement.

\section{A. Sequential Movement}

Sequential movement refers to that a batch of materials cannot be transferred to the next procedure before the previous procedure is completely finished. The processing cycle of a batch of materials under sequential movement form is:

$$
T^{\text {Sequential }}=n \sum_{i=1}^{m} T_{i}
$$

Where, $\mathrm{T}$ sequential - the production cycle of a batch of materials under sequential movement form;

n - material batch;

$\mathrm{m}$ - procedure number of materials;

$\mathrm{Ti}$ - time for single piece in each procedure

The strong point of this form is that the batch of materials can be processed continuously without stopping the machine, and the materials are transferred to the next procedure by batch, which is convenient for production organization. The weakness is that different materials have to wait for processing and transportation, so the production cycle is long.

\section{B. Parallel Movement}

Parallel movement form refers to that one piece of material of a batch should be sent to the next procedure for continuous processing immediately after the previous procedure is completed, to form cross operation.

$$
T_{\text {Parallel }}=\sum_{i=1}^{m} T_{i}+(n-1) T_{\max }
$$

Where, $\mathrm{T}$ Parallel - the production cycle of a batch of materials under parallel movement form;

n -material batch;

$m$-procedure number of materials;

Ti -time for single piece in each procedure;

Tmax - maximum time of single piece in the product processing procedure

The advantage of this form is no waiting in the procedure, so the production cycle of a whole batch of materials is the shortest. The disadvantage is that manual labor and equipment will stop when processing time of each procedure is different. Various working sites can produce continuously with adequate 
load only when the processing time of each procedure is equal. In addition, frequent material transport will increase transport volume and relevant expenses and costs.

\section{Parallel and Sequential Movement}

The parallel and sequential movement form refers to that each batch of materials is processed continuously on each procedure without pausing, and the processing of materials on each procedure is performed in parallel as much as possible. It has not only considered the coincidence of processing time of adjacent procedures, but also kept the sequential processing of this batch of materials in procedures.

The processing cycle of a batch of materials using parallel and sequential movement form is:

$\mathrm{T}$ parallel and sequential

$$
\text { T } \underset{\substack{\text { Parallel and } \\ \text { Sequential }}}{\text { T }}=\sum_{i=1}^{\mathrm{m}} T_{i}-(n-1) \sum_{i=1}^{\mathrm{m}}\left(T_{j}, T_{i}+1\right)
$$

Where, $\mathrm{T} \quad \begin{gathered}\text { Parallel and } \\ \text { Sequential }\end{gathered}$ - the production cycle of a batch of materials under parallel and sequential movement form;

$\mathrm{n}$-material batch;

$\mathrm{m}$-procedure number of materials;

Ti -time for single piece in each procedure, $i$ and $i+1$ represents the adjacent two procedures.

Its production cycle is longer than that of the parallel movement form, but adequate load of equipment can be ensured. Its features include:

When $\mathrm{Ti} \leq \mathrm{Ti}+1$, transfer the materials by parallel movement form, namely, each piece of material should be transferred to the next procedure immediately after completion of processing in the previous procedure when the processing time of previous procedure is less than or equal to the processing time of next procedure.

When $\mathrm{T} i \geq \mathrm{T} i+1$, take the completion time of the last piece of material in i procedure as a reference, and push backward, take $(n-1) T i+1$ as the start processing time of $i+1$ procedure.

This form absorbs the advantages of the first two movement forms, and has eliminated the intermittent pause, making the operation be loaded adequately. The procedure cycle is short, but it is complex to arrange the schedule (time organization).

The above three movement forms have their own strong points and weaknesses. When arranging the material schedule, the size of material, processing time of material, batch size and space organization form of production logistics should be considered. Generally speaking, the sequential movement form is suitable for small batch, small sized material or light material with short processing time; as for the parts in urgent need, the parallel movement form or the parallel and sequential movement form can be adopted.
As for enterprises of different types, the time organization form of production logistics is flexible and changeable. Time organization of production logistics aims to accelerate the circulation speed of materials in various procedures under the precondition that the equipment is fully loaded.

\section{PERSONNEL ORGANIZATION AND OPTIMIZATION OF PRODUCTION LOGISTICS}

Personnel organization of production logistics mainly reflects in the post design of operators. To realize the organization form optimization and coordination of production logistics in the aspects of space and time, the working post should be redesigned, so as to ensure optimized and smooth production logistics.

The human resource management theory advocates considering technical factors together with the behavior and psychological factors of human for post design. According to the characteristics of modern production logistics, the basic principle of post design should be "setting up the post in accordance with material flow direction instead of personnel, equipment or organization". Therefore, the following problems should be considered:

Number of posts to be set conforms to the principle of shortest material flow path; all posts should realize the effective coordination of various technologies (the objective is to ensure the realization of general production goal and task); each post should play a positive role in material flow (the objective is to coordinate and unify the relation between posts); all posts should reflect the economic, scientific and reasonable system principle in the material flow process (the goal is system optimization).

\section{A. Personnel Organization Content}

Post design should also conform to the worker's working motivation demand according to the behavioral and psychological characteristics of human. Therefore, we should start from three aspects:

(1) Expand the working scope, enrich the working content and arrange the work reasonably, aiming to increase the working scope and responsibility of the post, change the personnel's feeling of boredom towards work, get physical and mental development, so as to improve production efficiency and promote completion of tasks of the post.

(2) Work with full load, aiming to establish reasonable production quota and determine number of posts and demand for personnel.

(3) Optimize production environment, aiming to improve various factors in the production environment and establish the optimal system of human-machine-environment.

\section{B. Personnel Organization Requirements}

Post design reflects in the three space organization forms of production logistics and has different requirements for personnel:

(1) For the production logistics organized by technology specialization forms, the staff are required to have high 
specialization level and multiple skills, namely specialized in one field with multiple skills, one personnel multiple posts.

(2) For the production logistics organized by object specialization, the staff are required to have strong "workflow coordination" ability, so as to balance the "bottleneck" among various procedures on their own, and to ensure the proportion and timeliness of material flow.

(3) For the production logistics organized by group technology forms, the personnel are required to be authorized. In other words, to make sure everyone is equipped with technical data, tools, job responsibilities and rights by management and technology, to change the work habits and organization forms which are not beneficial to reasonable material flow, and to strengthen learning and utilization of new technology.

\section{CONCLUSION}

Under the background of global resources and energy shortage and increasingly intensified ecological environment restrictions, the survival and sustainable development of manufacturing enterprises is closely related to rigid restriction of resources and environment. To transform the raw materials into finished products needs multiple production links, long production cycle, large amount of resource and energy consumption, and high production cost. Modern manufacturing industry is most interest in how to provide the optimal products and services using lowest cost and consumption. The enterprises must transform the development form in true sense, and enhance the production and operation quality relying on technology progress and management innovation, so as to strengthen the market competiveness.

As a result, it is an important path for the realization of sustainable development of manufacturing enterprises by scientific organization and optimization of production logistics process, reduction of unit energy consumption and the formation of low-carbon production logistics mode under the low-carbon economic environment.

\section{REFERENCES}

[1] Gong Hua, Xu Ke. Theory and Method of Production Logistics Optimization of Manufacturing Enterprises [M]. Beijing: National Defense Industry Press, 2015: 5-7. (in Chinese)

[2] Tang Yonghong. Production Logistics Management Logistics [M]. Nanjing: Nanjing University Press, 2017: 61. (in Chinese)

[3] Yuan Yu, Shao Lei. Production Logistics Management [M]. Beijing: People's Communications Press, 2013: 257-259. (in Chinese) 